\title{
Countermeasure Analysis on Improvement of the Language Application Ability of College Students
}

\author{
Juan Liu \\ Heihe University \\ Heihe, China 164300
}

\author{
Jing Li \\ Heihe University \\ Heihe, China 164300
}

\begin{abstract}
Colleges and universities should pay more attention to the cultivation of comprehensive quality of college students. The language quality of college students is an important embodiment of the comprehensive quality. So by analyzing the present situation and existing problems of the application of the language and character of the college students, this paper summarizes the methods and measures to improve the application ability of the language and character of the college students.
\end{abstract}

Keywords-college students; language and writing; application ability; countermeasure analysis

\section{INTRODUCTION}

Strengthening the language application ability of college students is the need to promote the transition from examoriented education to quality education. Learning Chinese is not only necessary for speaking and writing, but also related to the overall quality of a person. As a university that trains highquality talents, it is obliged to guide college students to learn Chinese language and promote the transition from examoriented education to quality education. From the perspective of student employment, with the development of the economy, society's requirements for talents become increasingly higher. For example, a college student who studies finance can not only deal with the digital accounts after employment. Regular financial analysis and financial summary also require excellent writing ability in language and language. Therefore, it is necessary to pay attention to the improvement of college students' language application ability.

\section{THE PROBLEMS AND ANALYSIS OF LANGUAGE APPLICATION IN COLLEGE STUDENTS}

\section{A. The Problems in the Language Application of College Students}

1) The awareness of language norms is weak: Such problems as Stroke order upside down, the simplified and traditional style is mixed and used indiscriminately, incorrect punctuation, irregular spelling of Chinese pinyin and so on have become common problems in the use of language by contemporary college students. Besides, in terms of ideological concepts, college students do not attach much importance to the standardized use of language.
2) The decline in enthusiasm for learning Chinese: Yu Guangzhong, the writer, once sighed in the article of the Decline of the Chinese Language, lamenting the decline of the mother tongue ability of the modern Chinese. This state of affairs is related to the idea that finding a job with a high gold content more requires English and computers. Under the influence of this concept, some students will ignore the training of basic Chinese skills, and they will not focus on word-making and correcting typos.

3) The worrisome use ability of words: Some people have investigated the current situation of the ability of college graduates to express their writing skills. The survey results show that only $12.3 \%$ of college students' writing ability is acceptable, and that $70.4 \%$ of them are dissatisfied with the ability of language and language application of college students. The decline in language expression ability is mainly manifested in the following aspects: poor Chinese vocabulary; low writing ability; poor oral expression; unwritten writing and lack of aesthetics.

4) The decline in the writing ability of Chinese characters. Problems such as forgetting words, writing typos, and stroke order error are common among college students. Among them, the phenomenon of Chinese characters forgetting words is the most frequent, which is a common and universal problem. The second is the writing typos, which is also a very common problem. Stroke order errors are not very common, but they occur frequently.

5) The probability of writing is reduced: According to the survey, only one-fifth of the students who write frequently write, and one-third of the students basically do not write unless necessary (such as the exam), and one-half of the students will take notes during class. In addition to the special requirements for handwriting, the teachers 'homework will be completed by the computer, and the vast majority of students choose the intelligent pinyin input method, which also reduces the students' understanding and memory of Chinese characters.

\section{B. The Analysis of College Students' Language Proficiency}

1) The bias of relevant policies: At present, the reason why students do not pay attention to the improvement of language application ability is related to domestic policies to some extent. At present, the entire society pays attention to science and ignores liberal arts. From the funding of scientific research, it can be seen that the Ministry of Education has allocated a large amount of research funds for science and engineering, 
while the research funds for humanities and social sciences are much less.

2) The confusion of the words used in society: The social environment has a subtle influence on the language use of students. The current state of language use challenges traditional languages. In various advertising slogans on the street, typos are not uncommon, and even in the large-scale governmental publicity slogans, there are often irregular texts.

3) The impact of Internet language: In addition to updating media means, the creation of the Internet has also brought unexpected impacts on Chinese. Internet language has seriously impacted the current language and text teaching work. Li Rulong,a professor at Xiamen University, believes that Internet language is a pollution to Chinese. It is a language created by small groups for the convenience of group communication and based on their own hobbies. This is a sign of unhealthy conditions. From the current situation, the emergence and abuse of Internet language has had a negative impact on college students. In addition, college students often use computers to do their homework and write articles, and the input method software of electronic products, such as computers and mobile phones, often has the function of automatically recognizing and correcting typos, so that the sensitivity of college students to typos is getting lower and lower. With the development of science and technology, the Internet is becoming more and more popular, and the Internet buzzwords are frequently appearing in people's eyes. They are misleading while bringing novelty to students.

4) The crux of language education: College students have received many years of language education before entering school. In theory, the use of Chinese language should reach a higher level. However, many college students' language application ability is not satisfactory. In the middle school stage, most students spend their main energy on studying subjects, and few students concentrate on studying Chinese; Secondly, colleges and universities ignore the improvement of college students' ability of language application. For example, from the perspective of curriculum setting, most schools rarely offer or do not offer courses in improving language application ability. As the only course to improve language application ability, University Language has long been marginalized in some universities.

5) The omission of teaching management: There is no clear restriction mechanism for the non standard use of the language of the students, which makes the students produce the idea that the standard of language use will not affect the academic evaluation, which creates conditions for college students to understand the arbitrariness of language use. For example, in the graduation season, graduates are faced with the graduation exams, interviews, and so on, so there is no energy to write the paper, only to finish it at the deadline; even if there are several typos in the paper, the school still allows the students to graduate, which makes the language irregular phenomenon deeply rooted in the campus.

6) The impact of the campus environment: First of all, many teaching processes are gradually completed by computer, various notifications and publicity are mostly printed, and handwriting is rarely used. School is the main place for
Chinese character writing education. It is very important to create environment and atmosphere. Secondly, multimedia teaching is the preferred form for university teachers to teach. Few teachers influence students through standardized and well-organized blackboards, so the role of teachers in the writing of Chinese characters is reduced.

\section{MEASURES TO IMPROVE THE LANGUAGE APPLICATION ABILITY OF COLLEGE STUDENTS}

\section{A. To Enhance the Understanding of the National Language}

The famous German linguist Humboldt said: "Language seems to be the external manifestation of the national spirit. The national language is the national spirit, the national spirit is the national language. The degree of unity is more than anyone's imagination."Language is a communication tool and a social culture. Language has a strong cohesion and enlightenment for cultivating the national spirit and nurturing the national complex. If the foreign language is overemphasized, people will lose sight of the roots of their own language and affect the purity and sustainable development of the national culture. This unintentional self derogation ignores and neglects of national culture. It will make the next generation lack the sense of national pride and superiority, and leads to a tilt in their outlook on life and the world.

\section{B. To Guide College Students to Pay Attention to Chinese Learning}

Although the relevant language and legal policies have been formulated in China, due to the poor popularization, the weak implementation, the impact of English on Chinese, the confusion of social words and the abuse of the Internet language and so on, it has led to the weakening of Chinese language and the frequent occurrence of language irregularities. These phenomena cannot be reversed or avoided by individuals or groups. It requires the correct guidance of national policies. In the questionnaire survey, non-Chinese majors believe that if they want to improve their language ability, "Chinese language courses should be introduced as a compulsory course and some Chinese language test should be set up." Chinese majors also believe that "Chinese language majors should be added to the grade examination", or "set up the related examination, language subjects should be tested in the college entrance examination" and so on, setting Chinese grade examination is also a way to cultivate the language ability of college students. In addition, the state should continue to attach importance to the promotion of Putonghua, pay attention to the formulation of various applicable normative standards in social language life, and raise the people's awareness of language norms and language national consciousness.

\section{To Improve the Awareness of College Students on Language Norms}

Colleges and universities should strengthen the publicity and popularization of language norms and standards, so that students can fully understand the importance of language norms and consciously abide by the norms. It is necessary to 
use the opportunities such as classrooms and lectures to publicize and introduce the laws, regulations, standards and regulations on language and language issued by the State, such as the Law of the National Commonly-Used Language and Script, and provide students with reference to the words used in the standard language. College teachers should set an example, and teaching language should be strictly standardized, so that students pay attention to language norms.

\section{To Link the Correct Application of Language with Examination and Assessment}

The school publishes relevant rules on the language use of graduate papers, that is, the introduction of Putonghua and written normative words into the teaching plan, linking the standardized application of students' language with the comprehensive quality evaluation; at the same time, the school should standardize the teacher's language, strictly demand the teacher's teaching plan, blackboard and other teaching words, and link the standardized use of teaching terms with the assessment.

\section{E. To Strengthen the Traditional Culture Education of College Students}

Traditional culture includes many aspects. On the university campus, students can be taught a full range of traditional culture. From a language perspective, writing teaching is more representative. Training college students in the ability of writing Chinese characters is helpful to improve students 'aesthetic ability and appreciation, and to cultivate students' good moral character and strong will. In writing teaching, the primary goal is to train students to learn to behave. Liu Gongquan has said that the heart regular pen is correct. Raise the awesomeness, remove kitsch, the process of learning to write is consistent with the process of moral education. In the present situation of promoting quality education, it is necessary to fully explore and give full play to the quality education function of writing teaching, and use it in practical teaching work, and strive to improve the overall quality of college students.

\section{F. To Build a Platform to Improve Language Literacy}

It is necessary to create a good learning atmosphere on campus to make students really willing to learn, which can be achieved through various forms, such as holding academic lectures, establishing a real literary club, or organizing activities with humanistic care. It can be started by the Department of liberal arts, open to the school and persisted for a long time. Schools can provide some funds to encourage students. These activities help to create an atmosphere. Under this circumstance, students are encouraged to enthusiasm and consciously contact the culture of the motherland, instead of being perfunctory because of the necessary courses. In addition, many lectures are held by famous scholars. Experts and scholars, combined with their own experience, expound their understanding of life and literature, which will bring great benefits to students. The school also has poetry clubs, literary clubs, drama clubs, calligraphy associations and so on, and occasionally organizes some activities, which can provide a platform for students to improve their language and literacy.

\section{G. To Increase the Reading of College Students}

In order to improve the ability of the students to use language, expand the vocabulary from the works of language masters, and comprehend the language application skills. The process of reading is the process of collecting materials. It must be good at comparing, distinguishing, and summarizing, sorting, synthesizing, and analyzing. Through careful and careful screening, useful materials are applied to speaking and writing. At present, in Colleges and universities, books related to English examination skills are very popular, while literary works are rarely read. There are many misconceptions about the understanding of literary works. Many students think that reading literary works is a kind of leisure activity when they are free. Study time is tight, and literary recreation is certainly not on the agenda. Reading is the key to improve the language application ability. However, some colleges and universities have carried out writing training among college students, but have ignored the reading of literary works. Therefore, their writing training can't receive real results.

\section{H. To Strengthen the Demonstration Role of Teachers}

Example teaching is more important than words, teachers should also pay attention to the improvement of their own Chinese character writing quality. Whether it is the blackboard writing in class or the homework grading after class, it is necessary to strive for correctness, standardization, and beauty, and truly play a leading role in making the students subtly affected. This is also a way to improve the ability of students to write Chinese characters.

\section{The Training of Basic Language Skills}

Language application skills can also be improved through scientific training. Therefore, it is necessary to formulate practical measures to guide college students to focus on the improvement of language application ability. Both science and engineering students and liberal arts students must strengthen the training of Chinese listening, speaking, reading and writing skills. Therefore, it is necessary to make full use of the two positions of classroom teaching and campus cultural activities to comprehensively carry out the training of basic language skills.

\section{CONCLUSION}

Language is the carrier of culture. The level of language application ability is directly related to the level of personal quality. Therefore, colleges and universities should deeply recognize the necessity of strengthening the language application ability of college students, and take effective measures to improve students 'language application ability, create a good language application environment for students, and enhance students' self-confidence in language application.

\section{REFERENCES}

[1] Wei Hui. Discussion on National Language Ability Construction [J]. Linguistic Sciences, 2014, 1. 魏晖. 国民语言能力建设刍议[J].语言科 学, 2014, 1 . 
[2] Li Aihua, Wang Feixue. On Language Training in Chinese Teaching in Teachers Colleges[J].Journal of Liaoning Teachers College(Social Science Edition),2014,1. 李爱华, 汪飞雪. 谈师范院校语文教学中的 语言文字训练 [J].辽宁师专学报(社会科学版), 2014, 1 .

[3] Chen Muzhen. Implementing "Combination of Teaching, Learning and Working" to Improve the Ability of Language Writing[J].Journal of Zunyi Normal College,2014,6. 陈慕贞.实施”教学做合一”提升语言文 字应用能力[J].遵义师范学院学报, 2014, 6 . 